\title{
XVII. The pitted surface of meteorites
}

\section{N. Story Maskelyne F.R.S.}

To cite this article: N. Story Maskelyne F.R.S. (1876) XVII. The pitted surface of meteorites , Philosophical Magazine, 2:9, 126-131, DOI: 10.1080/14786447608639174

To link to this article: http://dx.doi.org/10.1080/14786447608639174

曲 Published online: 13 May 2009.

Submit your article to this journal $\pi$

Џ Article views: 2

Q View related articles $\sqsubset$ 
normal and two tangential, and that the normal axis differs more from the others than they differ from one another.

Some kinds of starch have grains of more irregular shape than those treated of; but their optical effects may be explained in the same manner.

This conclusion seems to agree with that arrived at by, Nägeli and Schwendener: see Sach's 'Textbook of Botany, p. 588 .

24 Hyde Terrace, Leeds.

XVII. The Pitted Surface of Meteorites.

$B y$ N. Story Maskelyne, F.R.S. \&c.

To the Editors of the Philosophical Magazine and Journal. GenTLEMEN,

TN the Comptes Rendus for April 24th of this year M. 1 Daubrée, the eminent director of the École des Mines, has offered an explanation of the hollows which characterize the crusted surface of meteorites. This explanation he partly draws from the very singular parallelism between this alveolar surface of moteorites and that presented by the fragments of unburnt gunpowder that fall at some distance from the muzzle of a large piece of ordnance.

I had myself the pleasure of introducing this subject to the notice of my friend M. Daubrée when he was staying with me in London in the summer of last year. I drew his attention to the remarkable similarity which these incompletely burned fragments of gunpowder bear in the pitted character of their surfaces to meteorites, whose black crust presents hollows and irregularities curiously identical in feature with those of the powder fragments.

I spoke, indeed, with some hesitation as to the causes of this similarity in the two cases, as the conditions were by no means identical. Had M. Daubrée's explanation been in all respects in accord with what seemed and seems to me the most satisfactory way of accounting for phenomena so similar, it would be unnecessary for me to make any further observation on the matter.

I should merely have been anticipated in the publication of one of the points I have discussed in a little treatise on meteorites long nearly ready for printing.

Since, however, M. Daubrée does not give the same explanation of the hollows pitting the surface of a meteorite that still appears to me to be, on the whole, the best way of accounting for them, I venture to put on record, earlier than I otherwise had intended doing, what I conceive is the pro- 
bable cause of the variolar surface in the two cases, and in what respects I find myself not in accord with the conclusion of the Director of the Ecole des Mines.

And I should here say that I have had, on more occasions than one during the last two or three years, to thank my friends Professor Abel and Major Noble for specimens of these fragments of gunpowder as projected from the 35-ton and 80-ton guns at Woolwich, and that in the explanation I offer of this part of the questions at issue my opinion has been brought into its present shape by the free communication of theirs, of which I trust it will be a fair representation.

The fragments are generally about the size of a small nut, and very irregular in form; but where the original grain of the gunpowder had a definite geometrical shape, this shape is distinctly recognizable in the diminished fragment which represents it.

The surface of the fragment is usually covered with a sort of irregular reticulation composed of hollows which, though sometimes isolated and nearly hemispherical, more often are seen to become confluent while remaining comparatively shallow. Sometimes a surface is met with that is smooth and unindented. Any one familiar with the aspect of a stone meteorite (an aerolite) will recognize at once the similarity of this description to that of the black incrusted and indented surface of one of these curious bodies. Those who are unfamiliar with this very characteristic feature of a meteorite can see it abundantly illustrated in the collection at the British Museum. Such, I may add, is the resemblance of the gunpowder fragment to a small meteorite, that three years ago, when I placed one of these powder-grains in the hands of Mr. T. Davies, the experienced assistant in the Mineral Department at the British Museum, he exclaimed, "What a beautiful little specimen of the Cold Bokkeveldt meteorite! how remarkably well it is indented!"

One would suppose that such a similarity in the two kinds of object must both be due to a similar cause, and the more so as in each case we have an accompaniment of detonation with enormous velocity and sudden differences of temperature and pressure; and yet this parallelism of cause may nevertheless not be quite so complete as is that of the effects in the two cases.

Among the many splendid services which Professor Abel has contributed, not only to the War Department at Woolwich, but at the same time to science, rank his studies, extended over many years, of the various conditions for and results of the combustion of explosive agents, including gunpowder. 
He showed that by simply removing the gases rapidly enough, as in an exhausted vessel, you might arrest entirely the combustion of gunpowder - and, further, that another element in the rapidity with which the combustion penetrates a solid mass of that explosive is the density of the mass. The huge cubes of nearly two inches, no less than the other varieties of "pebble" and "prismatic" forms of coarse-grain powder employed in our large guns are, by their very manufacture, lacking in mechanical homogeneity.

Within the gun, where the pressure is some twenty-two or twenty-three tons to the square inch, the process of combustion goes on rapidly, but can be regulated by adjusting the density; and size of the gas-producing grains of gunpowder. It furthermore goes on with greater intensity at some than at other parts of the surface, in consequence of the variations in density; and at these points centres of combustion become established-the relative depths in different parts of the surface to which the combustion would penetrate in any brief period depending on the relative densities of the ingredient granules or fragments of "cake," which give to the gunpowder mass the character of a sort of breccia. At the discharge of the gun the released gases escape, together with a few fragments, which are the cores of some of the cubes of gunpowder which have not had time to be entirely consumed; and at the surface of these fragments the combustion will proceed at different centres of combustion, the depth of which depends on the density of the powder and the pressure exerted on it by the surrounding gases.

At the same time the sudden removal of the vast pressure in operation within the gun, and an initial velocity of 1400 feet in a second, sufficiently explain, on Professor Abel's principle, the extinction of the combustion of these projected fragments. Their pitted surfaces are also explained as the result of mechanical heterogeneity in the component particles of the powder.

With these points M. Daubrée appears to be in accord, though he does not seem to have been aware of Professor Abel's researches, as he does not refer to them.

Let us now turn to the case of a meteorite. It enters our atmosphere with at least a planetary velocity, which is at once arrested by the resistance the body experiences in traversing even the highest and rarest region of the aerial envelope of our globe.

The resulting heat at once fuses the surface of the stone or iron; and though the fused and oxidized material is thrown off (aided in most cases by a rotatory movement in the mass) as 
rapidly as it is formed, the heat must quickly begin to penetrate towards the interior of the body, even where its ingredients offer so inferior a conducting-material as spherules of magnesian or ferro-magnesian silicates united in different degrees of aggregation, and, indeed, often forming a very incompact structure. The explanation I have heretofore offered of the "pitting" of the surface of a meteorite was, that the want of homogeneity of the mass permitted the heat to penetrate more rapidly from its exterior in some places than in others, so that the sudden expansion due to the almost instantaneous accession of enormous temperature on the surface of the stone tore out small pieces of it and flung them off from the swiftly moving mass, the interior of which must be presumed to be the more brittle from the meteoric body entering our atmosphere with the temperature of the "cold of space" (see Phil. Mag. January 1863). Even were one large outer shell from this cause to break away from an inner core, we should expect the surfaces to present projections and depressions corresponding in part to the denser or less dense, the better or the less well conducting parts of the mass, and partly also of course to any directions of weaker cohesion in the stone arising from other causes.

The greater fusibility of some than of other of the mineral ingredients of the meteorite (for instance, of the more ferrous as compared with the less ferrous and more magnesiferous silicates) may in certain cases explain some of the peculiar pitlike indentations, as, for instance, those in which a rather deep irregularly shaped hole is met with, perhaps half an inch in depth ; and in the fusion and reincrustation of a freshly broken. surface, after explosion and fracture, this cause possibly helps in increasing the variolar irregularities of the surface. Another cause of these irregularities suggests itself in the differences of combustibility of the ingredients of a meteorite; for, in a strict sense of the word, in most meteorites the bulk of the ingredients-all in fact except the purely magnesian or calcio-magnesian iron-free silicates-are combustible, $i$. e. can undergo further oxidation; for this is true, be it remembered, not merely of the iron and the troilite ( $\mathrm{FeS}$ ), but also of the magnesio-ferrous silicates bronzite and olivire. But I cannot believe that this is an active agent in the pitting of the surface, however it may contribute to the brilliancy of the fiery meteor. For it is no uncommon thing to find enclosed in the black oxidized glaze of a meteorite little pepites of nickel-iron unoxidized; and in the Busti meteorite the yellowish glaze covered alike the augite and the Oldhamite (CaS), without offering any indication of the latter having been burned awayPhil. Mag. S. 5. Vol. 2. No. 9. Aug. 1876. 
and of hollows being formed at the spots where the crust enclosed or was underlain by spherules of the sulphide.

In general I see no reason to believe that the oxidation penetrates below the thin pellicle of oxidized crust or enamel that perpetually forms over and protects the interior of the stone or iron mass, and so often even encloses unchanged particles of its most oxidizable ingredients. That the character of the pitting which the surface of a meteorite undergoes does not depend so much on the combustibility of its ingredients as on their mechanical aggregation, seems further to follow from the fact that the carbonaceous meteorites are not more pitted (generally, I think, less so) than those which are free from carbon, while, on the other hand, the more compact meteorites, but, I should add, also those containing least of felspathic ingredients (the incrustation of the more felspathic varieties being usually a once very fluid glaze), are those which offer the most pitted surfaces. The meteorites of Iowa, Gopalpur, Pultusk, and the marbled or brecciated stones of Maza Koorna, Aldsworth, and Parnallee may be instanced in confirmation of this ; while the softer and less compact aggregates of meteoritic matter, of which the Nellore and Busti meteorites are examples, present but little pitting on their surfaces.

I believe, then, that it is to the difference in the mechanical facility with which the sudden heat penetrates the mass at different points on its surface, partly as a consequence of greater conductivity, partly of greater fusibility, that the melting-out and immediate dissipation in the air of the material at those parts is mainly due, and that it is in no degree due to the greater combustibility of the mass at those points.

M. Daubrée, on the other hand, does not believe that the "pitting" is due to the sort of splintering effect of enormous heat suddenly applied, because he has failed in producing an analogous surface by plunging various kinds of rock into a furnace at the Conservatoire des Arts et Métiers ; in which, however, the contrasts of temperature and mechanical means. of momentarily removing the fluid incrustation are absent from the experiment, even if the characters of the rocks were strictly comparable. M. Daubrée, however, offers another explanation of the phenomenon; and this at least is one which it would be difficult to refute by the repetition of the conditions in an ordinary experiment. His view is, that the hollows formed on the surface of the meteorite are produced by a sort of boring action effected by the air compressed and fiercely agitated into gyratory motion by the rapidly moving stone. "En tourbillonnant ainsi sous de telles pressions, l'air tend à tarauder," he says, and considers this mechanical action to be assisted by the che- 
mical combustion of the iron and troilite contained in the meteorite. The last point has been already considered; on the other I have only to observe that, were the hollowing-out of a meteorite due to such little whirlwinds on its surface, we should find traces of the rotatory action in a whorl-like distribution or marking of the crust. We do not find this, whereas we do find very often distinctly marked traces of the orientation of the meteorite at a given period in its course, indicated by the backward flow of the then molten crust, which, like some old lava stream in petto, still presents lines following the course of that flow on the surface, and a denser incrustation in the rear than on the front, from which the backward-streaming lines take their course.

The subject here discussed, however, is bound up with questions as to the original form in which meteorites enter our atmosphere, questions that have recently been discussed from two very opposite points of view by F. Mohr in Liebig's $A n$ nalen (vol. clxxix. pp. 257-282), and by Professor Tschermak, in the June Supplementary Number of the Philosophical Magazine for this year. I will take a nearly opportunity of asking you to record my views on both of them.

I am, yours \&c.,

N. Story Maskelyne.

112 Gloucester Terrace, W. July 17, 1876 .

\section{On the Elasticity of Brass.}

By Lieut.-Col. A. R. Clarke, C.B., R.E., F.R.S., \&c.*

$\mathrm{N}$ the course of a recent measurement of the distance be1 tween the knife-edges of Kater's Pendulum, it became necessary to consider the question of the change of length which takes place when the position of the pendulum is changed from vertical to horizontal, and also the alteration in length caused by interchanging the knife-edges in swinging. The values of the modulus of elasticity which are found in the ordinary books of reference are given, so far as I have seen, without any statement of the authority on which they rest; and it does not appear that any precise experiments have been made in this country on the elasticity of brass, though those of iron and steel are well determined. Some circumstances having led me to doubt the accuracy of the value taken from the Table, a simple experiment on the flexure of a brass scale was made, which gave a very different value.

In order to get some precise results, I obtained four speci* Communicated by the Autbor.

K 2 